\title{
Multiple polypoid colonic metastases from rectal adenocarcinoma with signet ring cells features: a case report
}

Yunlong $\mathrm{Wu}^{1 \dagger}$, Jiaolin $\mathrm{Zhou}^{1 \dagger}$, Tongtong $\mathrm{Liu}^{2}$, Lai Xu ${ }^{1}$ and Yi Xiao ${ }^{1^{*}}$ (D)

\begin{abstract}
Background: Multiple polypoid colonic metastases are very rare which mainly originated from gastric carcinoma or melanoma. For rectal cancers, liver, lung and peritoneum are the most common metastatic sites. Here we present an unusual case with rectal adenocarcinoma and metachronous multiple colonic polypoid metastases.

Case presentation: A 53-year-old man who underwent radical resection for rectal cancer 2 years ago was admitted to our department for an elevation of CEA level of $18.4 \mathrm{ng} / \mathrm{ml}$. Colonoscopy revealed ten ivory rubbery colonic polypoid lesions (about $5 \mathrm{~mm}$ in diameters) in the large bowel which were confirmed as signet ring cell carcinomas (SRCC) by biopsy, but full-body contrast enhanced CT and PET-CT showed no other suspicious lesion. Seven weeks later, a laparoscopic total colectomy was performed and more than 50 polypoid lesions were observed throughout the mucosal surface of the large intestine which were confirmed as metastatic SRCC by postoperative pathological examination. All the 34 paracolic lymph nodes retrieved were involved. After 4 months, diffuse abdominopelvic and multiple bone metastases were identified by $\mathrm{CT}$ and the patient died of the disease 1 month later.
\end{abstract}

Conclusion: Here we present an unusual case of multiple colonic polypoid metastases of rectal adenocarcinoma. For SRCC that is prone to have disseminated micrometastases, colonic'polyps' may be the early noticeable sign of undetectable and extensive tumor spread. Instead of surgical resection of 'the confined disease in colon', systemic treatment maybe a more appropriate choice.

Keywords: Rectal cancer, Signet ring cell carcinoma, Metastasis, Endoscopy, Imaging studies

\section{Background}

Multiple polypoid colonic metastases from other distant gastrointestinal carcinomas are extremely rare, only a few cases have been reported in the literatures [1-7]. Among these cases, colonic metastases were mainly originated from gastric carcinoma or melanoma, with signet ring cell features being the most common histological type.

\footnotetext{
*Correspondence: xiaoy@pumch.cn

†Yunlong Wu and Jiaolin Zhou have contributed equally to this work

1 Department of General Surgery, Peking Union Medical College Hospital,

Peking Union Medical College, Chinese Academy of Medical Sciences, No.

1 Shuai Fu Yuan, Dong Cheng District, Beijing 100730, China

Full list of author information is available at the end of the article
}

Signet ring cell carcinoma (SRCC) is a rare subtype of colorectal cancer, accounting for about $1 \%$ of all rectal cancers $[8,9]$. Patients with SRCCs often present with distinct clinical features and poor prognosis [10,11].

The most common sites of metastases from rectal cancer are the liver, lung, and peritoneum. Here, we report an unusual rectal cancer case with metachronous multiple colonic polypoid metastases.

\section{Case presentation}

A 53-year-old man with progressive abdominal pain and distention was admitted to our tertiary care center on October 15, 2013. Colonoscopy revealed a rigid circumferential neoplasm in the rectum about $8-9 \mathrm{~cm}$ from 
the anal verge, with an increased CEA level of $10.4 \mathrm{ng} /$ $\mathrm{ml}$. In addition, two sessile polys $(2-3 \mathrm{~mm})$ in descending colon were also found and removed by forceps during colonoscopy, which were pathologically confirmed as adenomas. MRI showed a circumferential thickening of the bowel wall (maximum thickness, $14 \mathrm{~mm}$ ), suggesting the diagnosis of malignant tumor (cT3NOMx). After three times of fruitless biopsies, which invariably revealing "inflammation", a transrectal incisional biopsy under the general anesthesia was performed and poorly differentiated adenocarcinoma was diagnosed. The patient received the neoadjuvant chemoradiotherapy (long-term radiation of $50 \mathrm{~Gy} / 25 \mathrm{f}$ with concomitant capecitabine) and followed by the radical abdominoperineal resection surgery. The postoperative pathology showed poorly-differentiated adenocarcinoma with signet ring cell features (staged ypT3N1b). Thereafter, the patient received six cycles of adjuvant single-agent chemotherapy (capecitabine), owing to his refusal of the recommended intensified regimens.

During regular follow-up, the patient was diagnosed with thrombocythemia and began to take hydroxyurea $1 \mathrm{~g}$ twice a day. Two years after surgery, the CEA level increased significantly from 2.9 to $18.4(\mathrm{ng} / \mathrm{mL})$. Colonoscopy revealed about ten polypoid lesions (about $5 \mathrm{~mm}$ in diameter), and the biopsies proved to be SRCC (Fig. 1). Imaging examinations including full-body contrast enhanced CT, PET-CT and gastroscope were then performed, with no other primary or metastatic foci being identified. The patient refused further systemic chemotherapy, but insisted on surgery. Two months later, a laparoscopic total colectomy with permanent ileostomy was performed. By examining the gross specimen, more than 50 polypoid lesions were scattered throughout

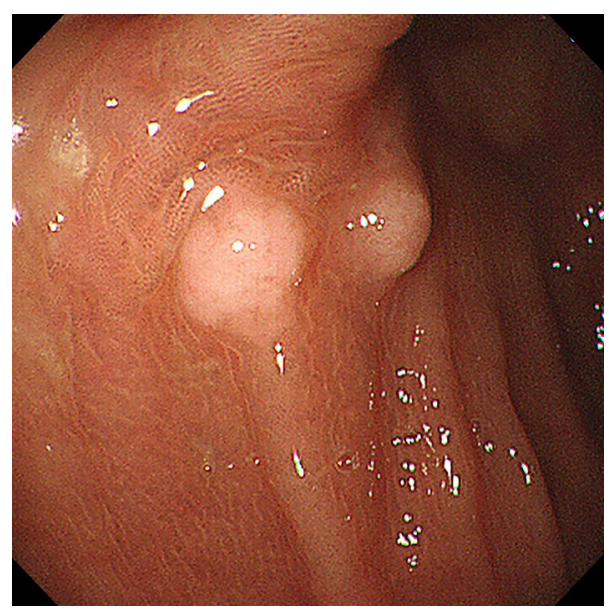

Fig. 1 Colonoscopy images showing multiple "polyps" throughout colon the colonic wall, ranging from 2 to $10 \mathrm{~mm}$ in diameter (Fig. 2a). Pathology showed multifocal signet ring cell carcinomas with some lesions involving the whole layer of colonic wall (Fig. $2 \mathrm{~b}-\mathrm{c}$ ), as well as a large number of metastatic nodules throughout the mesocolon. All the 34 paracolic lymph nodes retrieved were involved. Immunohistochemically, the metastatic tumors were CEA $($ focal +$)$, CK7 (-), CK20 (+), MUC2 (+), MUC5AC $(-)$, MUC6 (-), E-Cadherin (+), MLH-1 (+), MSH-2 $(+)$, MSH-6 (+), PMS-2 (+), Ki-67 index: 70\%. After 4 months, diffuse abdominopelvic and multiple bone metastases were detected through the $\mathrm{CT}$ and the patient died of the disease 1 month later.

In additional investigation by targeted next generation sequencing using a 1021-gene panel, somatic mutations of ALK, EPHB2, ERBB4, GRIN2A, PTPRD, TP53 were detected in tumor tissue.

Informed consent documents were provided by patients' surrogates.

\section{Discussion and conclusion}

Polypoid colonic metastases are extremely uncommon, which has been previously reported less than 10 cases [1]. In this case, the pathologic examination demonstrated the same histological type between the colonic polypoid lesions and the original rectal cancer. Also, other malignancies including the gastric cancer were excluded by the gastroscope and PET-CT. Besides, the immunohistochemical exam of the colonic metastases showed $\mathrm{CK}^{-}$/ $\mathrm{CK}_{2} 0^{+}$, which indicated the gastrointestinal origin [12, 13]. Therefore, we conclude that this is an extremely rare case of multiple polypoid colonic metastases from the rectal carcinoma with signet ring cell features.

Patients with SRCC often have distinct clinical characteristics and poor outcomes [11]. Evidence indicated that in comparison with well to moderately differentiated colorectal adenocarcinoma, SRCC was prone to have widespread peritoneal metastases, instead of common liver or lung metastases $[14,15]$. SRCC was believed to be associated with distinctive molecular features. Study have shown that tumor cells of SRCC have impaired expression of adhesion molecules including E-cadherin and $\beta$-catenin [16], which may attribute to the loose appearance and aggressive behavior. In this case, we found disseminated macroscopic metastases confined to the mesocolon and bowel wall during surgery. Whether these lesions spread via uncommon route, such as hematogenous or lymphatic spread through the submucosal or mesenteric vasculatures, is still elusive.

As the colonic polypoid metastases implied the wide spread of the disease, most of the previous cases were treated with a non-operative approach using systemic 


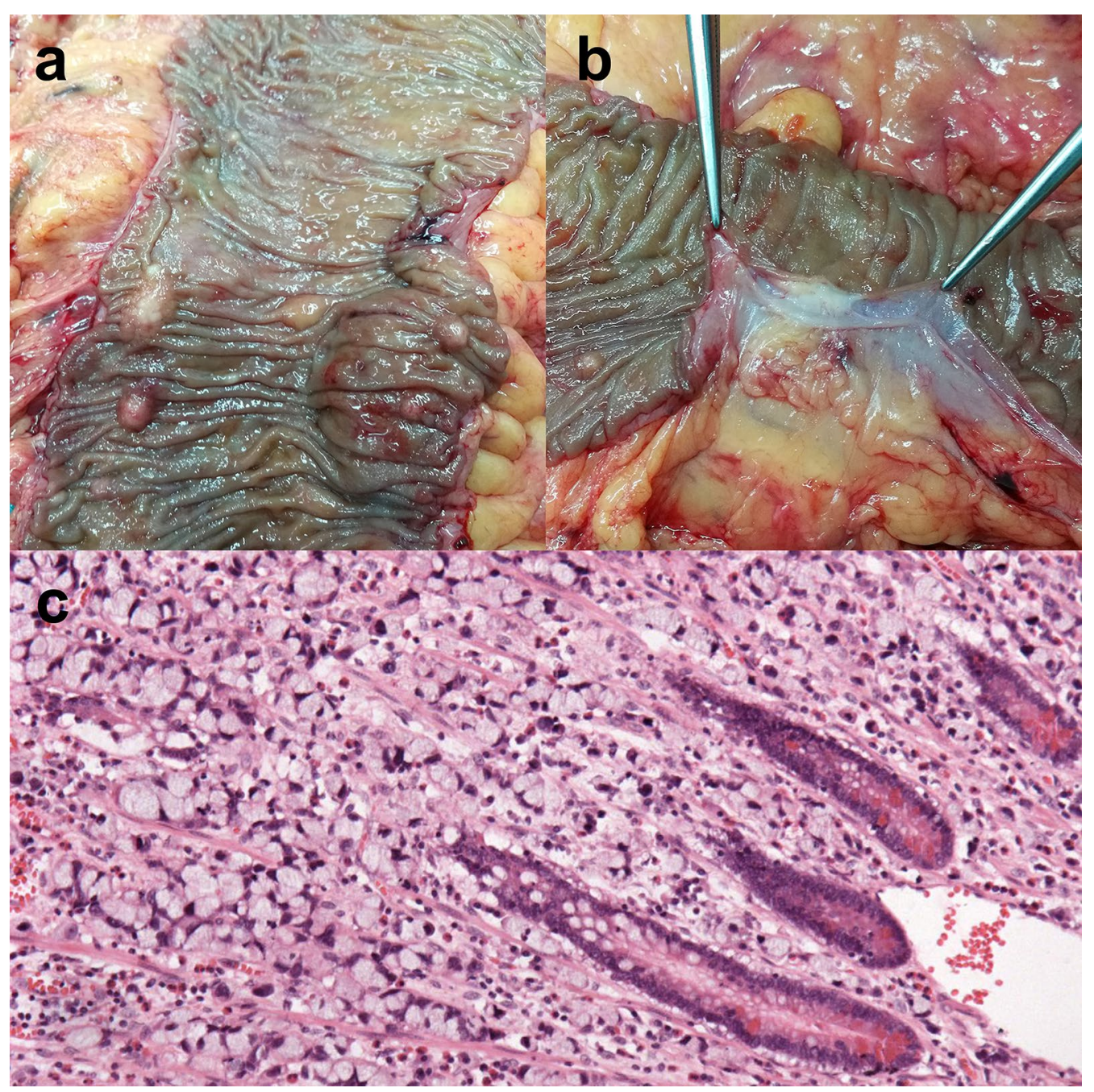

Fig. 2 The resection of entire colon showed multiple white polypoid lesions $(\mathbf{a}, \mathbf{b})$, and histopathological examination result revealing signet ring cells (c, hematoxylin and eosin staining; magnification, $\times 100$ )

chemotherapy $[1,5,6]$ or best supportive care [7], and the outcomes were diverse and poor.

In 2015, Hugen et al. [17] found that adjuvant chemotherapy could improve the survival of stage III colorectal signet ring cell carcinoma. A recent study also revealed that, compared with surgery alone, chemotherapy alone or combined with surgery may further improve the prognosis of SRCC patients with peritoneum metastases [18]. In this case, unfortunately, the unusual metastatic pattern and the false-negative imaging findings misguided the surgeons to perform an unbeneficial colectomy surgery. We suppose that the feature of micrometastases in SRCC make it difficult to identify the wide spread of the disease by imaging examinations, even in patients with heavy tumor burden.
In summary, the presence of multiple polypoid colonic metastases may represent a very rare condition of extensively systemic spread of SRCC. Even without evidence of involvement of other organs, we think there is no role for colectomy in this condition. Systemic treatment with intensified chemotherapy and new targeted therapies may bring a glimmer of hope for patients with such refractory cancer.

\section{Abbreviations}

SRCC: Signet ring cell carcinoma; CT: Computed tomography; MRI: Magnetic resonance imaging; PET-CT: Positron emission tomography-computed tomography; CEA: Carcino-embryonic antigen; CK7: Cytokeratin 7; CK20: Cytokeratin 20; MUC2: Mucin 2; MUC5AC: Mucin 5AC; MUC6: Mucin6; MLH1: MutL homolog 1; MSH2: MutS homolog 2; MSH6: MutS homolog 6; PMS2: Postmeiotic segregation increased 2. 


\section{Acknowledgements}

We are grateful to Dr. Yan Gao (Department of Gerontology, Inner Mongolia forestry general hospital) for collection of data.

\section{Authors' contributions}

YW and JZ collected the clinical data and wrote the manuscript. JZ and YX designed this study. TL and LX contributed to the management of the case, editing the manuscript and pictures. YX took charge of the clinical diagnosis and surgical treatment of the patient, who critically revised the manuscript as well. All authors have read and approved the manuscript.

\section{Funding}

N/A

\section{Availability of data and materials}

All data generated or analyzed during this study are included in this current article.

\section{Ethics approval and consent to participate}

Not applicable.

\section{Consent for publication}

Written informed consent was obtained from the patient's medical proxy (his wife) for publication of this case report and any accompanying images.

\section{Competing interests}

The authors declare that they have no competing interests.

\section{Author details}

1 Department of General Surgery, Peking Union Medical College Hospital, Peking Union Medical College, Chinese Academy of Medical Sciences, No. 1 Shuai Fu Yuan, Dong Cheng District, Beijing 100730, China. ${ }^{2}$ Department of Radiology, Beijing Chao-Yang Hospital, Capital Medical University, Beijing 100020, China.

\section{Received: 30 January 2020 Accepted: 8 October 2020}

Published online: 14 October 2020

\section{Reference}

1. Gao B, Xue X, Tai W, Zhang J, Chang H, Ma X, Qi Y, Cui L, Yan F, Pan L. Polypoid colonic metastases from gastric stump carcinoma: a case report. Oncol Lett. 2014:8(3):1119-22.

2. Sacks BA, Joffe N, Antonioli DA. Metastatic melanoma presenting clinically as multiple colonic polyps. AJR Am J Roentgenol. 1977;129(3):511-3.

3. Metayer P, Antonietti M, Oumrani M, Hemet J, Lemoine F, Basuyau J. Metastases of a gastric adenocarcinoma presenting as colonic polyposis_report of a case. Dis Colon Rectum. 1991;34(7):622-3.

4. Ogiwara H, Konno H, Kitayama Y, Kino I, Baba S. Metastases from gastric adenocarcinoma presenting as multiple colonic polyps-report of a case. Surg Today. 1994;24(5):473-5.
5. Tomikashi K, Mitsufuji S, Kanemasa H, Sakai M, Wakabayashi N, Tsuchihashi Y. Gastric cancer metastatic to the colon. Gastrointest Endosc. 2002:55(4):561.

6. Lee HC, Yang MT, Lin KY, Tu HY, Zhang TA, Chen PH. Metastases from gastric carcinoma to colon in the form of multiple flat elevated lesions: a case report. Kaohsiung J Med Sci. 2004;20(11):552-7.

7. Rodriguez Salas N, Gonzalez Paz C, Rivera T, Lopez Alfonso A, Martin Marino A, Lara Alvarez MA. Colonic anastomosis and colonic polyp mucosal metastasis of signet ring cell gastric adenocarcinoma. Clin Transl Oncol. 2010;12(3):238-9.

8. Kang H, O'Connell JB, Maggard MA, Sack J, Ko CY. A 10-year outcomes evaluation of mucinous and signet-ring cell carcinoma of the colon and rectum. Dis Colon Rectum. 2005;48(6):1161-8.

9. Wang R, Ma X, Li Y, He Y, Huang D, Cai S, Peng J. The characteristics and prognostic effect of E-cadherin expression in colorectal signet ring cell carcinoma. PLoS ONE. 2016;11(8):e0160527.

10. Wei Q, Wang X, Gao J, Li J, Li J, Qi C, Li Y, Li Z, Shen L. Clinicopathologic and molecular features of colorectal adenocarcinoma with signet-ring cell component. PLoS ONE. 2016;11(6):e0156659.

11. Sung CO, Seo JW, Kim KM, Do IG, Kim SW, Park CK. Clinical significance of signet-ring cells in colorectal mucinous adenocarcinoma. Mod Pathol. 2008;21(12):1533-41.

12. Chu P, Wu E, Weiss LM. Cytokeratin 7 and cytokeratin 20 expression in epithelial neoplasms: a survey of 435 cases. Mod Pathol. 2000;13(9):962-72.

13. Tung SY, Wu CS, Chen PC. Primary signet ring cell carcinoma of colorectum: an age- and sex-matched controlled study. Am J Gastroenterol. 1996;91(10):2195-9.

14. Pande R, Sunga A, Levea C, Wilding GE, Bshara W, Reid M, Fakih MG. Significance of signet-ring cells in patients with colorectal cancer. Dis Colon Rectum. 2008;51(1):50-5.

15. Benedix F, Kuester D, Meyer F, Lippert H. Influence of mucinous and signet-ring cell differentiation on epidemiological, histological, molecular biological features, and outcome in patients with colorectal carcinoma. Zentralbl Chir. 2013;138(4):427-33.

16. Borger ME, Gosens MJ, Jeuken JW, van Kempen LC, van de Velde CJ, van Krieken JH, Nagtegaal ID. Signet ring cell differentiation in mucinous colorectal carcinoma. J Pathol. 2007;212(3):278-86.

17. Hugen $\mathrm{N}$, Verhoeven $\mathrm{RH}$, Lemmens VE, van Aart CJ, Elferink MA, Radema SA, Nagtegaal ID, de Wilt JH. Colorectal signet-ring cell carcinoma: benefit from adjuvant chemotherapy but a poor prognostic factor. Int I Cancer. 2015;136(2):333-9.

18. Shi T, Huang M, Han D, Tang X, Chen Y, Li Z, Liu C, Xiang D, Wang T, Chen $Y$, et al. Chemotherapy is associated with increased survival from colorectal signet ring cell carcinoma with distant metastasis: a surveillance, epidemiology, and end results database analysis. Cancer Med. 2019;8(4):1930-40.

\section{Publisher's Note}

Springer Nature remains neutral with regard to jurisdictional claims in published maps and institutional affiliations.

Ready to submit your research? Choose BMC and benefit from:

- fast, convenient online submission

- thorough peer review by experienced researchers in your field

- rapid publication on acceptance

- support for research data, including large and complex data types

- gold Open Access which fosters wider collaboration and increased citations

- maximum visibility for your research: over 100M website views per year

At BMC, research is always in progress.

Learn more biomedcentral.com/submissions 